\section{Ecstasy (MDMA) and oral health}

\author{
H. S. Brand, ${ }^{1}$ S. N. Dun ${ }^{2}$ and A. V. Nieuw Amerongen ${ }^{3}$
}

VERIFIABLE CPD PAPER
IN BRIEF

- Ecstasy has a high frequency of oral side effects.

- These oral effects are mainly related to xerostomia and jaw clenching.

- Recent use of ecstasy may interfere with dental treatment.

- Saliva can be used for non-invasive detection of ecstasy.

3,4-methylenedioxymethamphetamine (MDMA), more commonly known as 'ecstasy' or XTC, is frequently used by young adults in the major cities. Therefore, it is likely that dentists might be confronted with individuals who use ecstasy. This review describes systemic and oral effects of ecstasy. Life-threatening complications include hyperthermia, hyponatraemia and liver failure. In addition, psychotic episodes, depression, panic disorders and impulsive behaviour have been reported. Oral effects include xerostomia, bruxism, and an increased risk of developing dental erosion. Mucosal changes have also been reported. Recent use of ecstasy may interfere with dental treatment. Finally, the potential use of saliva for non-invasive detection of ecstasy is discussed.

\section{INTRODUCTION}

3,4-methylenedioxymethamphetamine (MDMA, Fig. 1), more commonly referred to as 'ecstasy' or XTC, was patented in 1914 by the German pharmaceutical company Merck. Although MDMA is widely believed to have been synthesised as an anorectic, the actual patent does not make mention for such use., ${ }^{1,2}$

In the early 1960s, MDMA was rediscovered by Alexander Shulgin. This chemist synthesised myristicin into MDMA by extracting it from the oils of nutmeg and mace, and distributed the MDMA among befriended psychotherapists. They would administer the drug to their patients therapeutically to increase self-insight, enhance empathy and help the patient through emotional blockages. ${ }^{1-3}$

In the late 1970s, illegal production of MDMA started in California (USA). Sold

\footnotetext{
${ }^{1 *}$ Department of Dental Basic Sciences, Section of Oral Biochemistry and Department of Oral-Maxillofacial Surgery, Centre for Dentistry Amsterdam (ACTA), Amsterdam, the Netherlands ${ }^{2,3}$ Department of Dental Basic Sciences, Section of Oral Biochemistry

*Correspondence to: Dr H. S. Brand, ACTA, Medical Faculty, room A-220, Vrije Universiteit, Van der Boechorststraat 7, 1081 BT Amsterdam, The Netherlands Email: hs.brand@vumc.nl
}

\section{Refereed Paper}

Accepted November 2007

DOI: $10.1038 /$ bdj.2008.4

${ }^{\oplus}$ British Dental Journal 2008; 204: 77-81

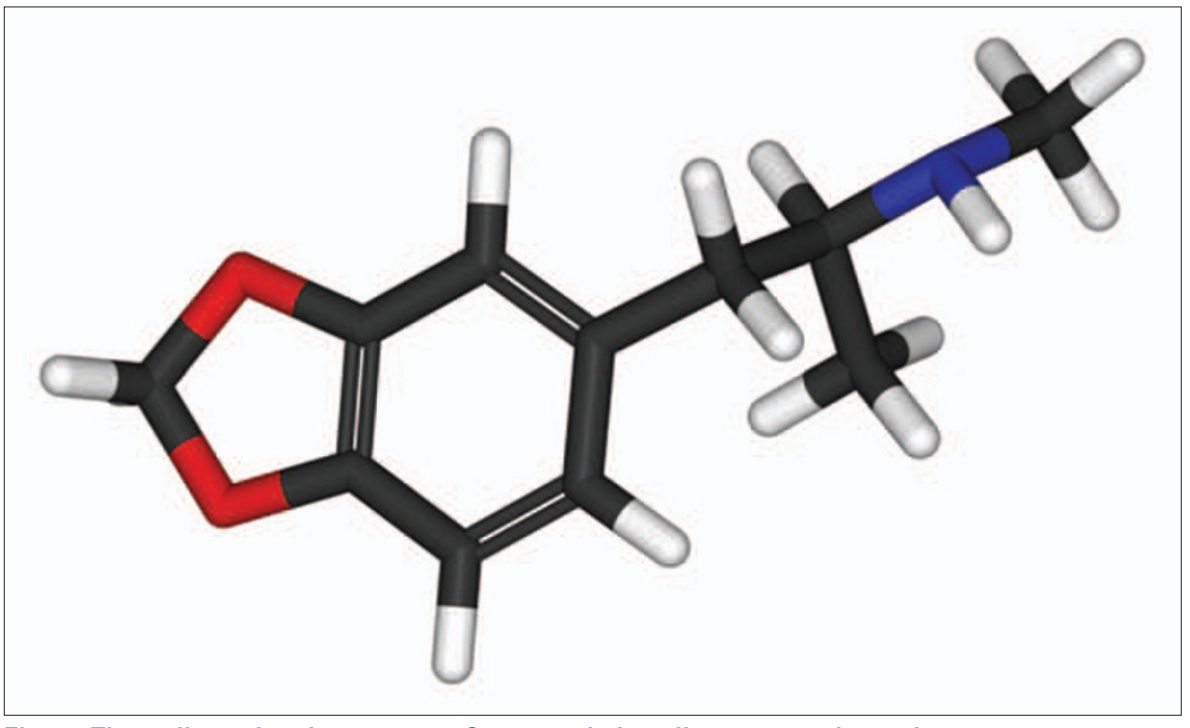

Fig. 1 Three dimensional structure of 3,4-methylenedioxymetamphetamine

as 'ecstasy', the drug was first used mainly at home. From the 1980s, ecstasy became increasingly popular among hippies, yuppies and students. A major factor was the emergence of 'house' parties, and the subsequent 'rave' scene. At 'raves', people would dance vigorously to the rhythmic beats and sounds of 'techno' music. Of subjects attending 'raves', approximately $90 \%$ report use of ecstasy. ${ }^{4}$

\section{Administration}

Ecstasy is normally sold as tablets, which have different colours, shapes and logos (Fig. 2). Tablets sold as ecstasy contain varying amounts of MDMA (typically 30-150 mg, on average 77 $\mathrm{mg}$ ) or none at all..$^{5}$ Ecstasy tablets may also contain other substances, such as methylenedioxyethylamphetamine, methylenedioxyamphetamine, methamphetamine, ketamine, caffeine and/or salicylic acid. ${ }^{5,6}$

Ecstasy is frequently used in combination with alcohol or other types of drugs, which can result in unpredictable effects. Ecstasy is usually combined with cannabis $(71 \%)$ or alcohol (66\%). A combination with amphetamine (29\%) or cocaine $(25 \%)$ is also frequently reported. ${ }^{7}$ 


\section{Ecstasy consumption}

In 1977, the United Kingdom Home Office listed MDMA as a class A drug under the Misuse of Drugs Act of $1971 .{ }^{4}$ Despite its illegal status, use of MDMA is widespread. The UK national criminal intelligence service estimates that 0.5-2 million tablets are consumed weekly in Britain. ${ }^{5}$

Following a massive increase in the 1990s from 1\% of the population in England and Wales in 1994 to 2.2\% in 2002, the annual prevalence rates of ecstasy had fallen to $1.6 \%$ by $2006 .{ }^{8}$ It is remarkable that use of ecstasy is relatively high among British dental students (6-8\%) and dentists (8-13\%). ${ }^{9-11}$

\section{Mechanism and metabolism}

MDMA causes a massive synaptic release of serotonin (5-hydroxytryptamine, 5HT) and, to a lesser extent, of dopamine and norepinephrine. Since MDMA also inhibits the reuptake transporters of the synapse, there is an acute increase in the intra-synaptic concentration of these neurotransmitters, followed by a period of depletion. ${ }^{4,5}$

Following oral ingestion of an ecstasy tablet, the effects begin after 20 to 60 minutes, peak after two hours and last four to six hours. The half-life of MDMA in plasma is six to nine hours. About $80 \%$ of MDMA is cleared metabolically in the liver, catalysed by the cytochrome P450 isoenzyme CYP2D6. The remaining $20 \%$ of the dose is excreted unaltered in urine, ${ }^{12}$ in which MDMA can still be detected two to three days after use. Ecstasy is also excreted in other body fluids such as tears, saliva, sweat and breast milk..$^{12,13}$

\section{Mental and physical effects}

Ecstasy has both physical and mental effects (Table 1). For example, ecstasy induces a euphoric feeling, suppresses tiredness, increases sensory perception and induces a sense of closeness to other people. Other symptoms are tachycardia, tremor, dilated pupils, an increased body temperature, nausea, suppressed appetite, insomnia and restlessness. Sometimes, body movements are difficult to coordinate. Several days after use of ecstasy, lack of energy, panic disorders, a depressive mood and difficulty concentrating may be present. . $^{1,4,5,14}$

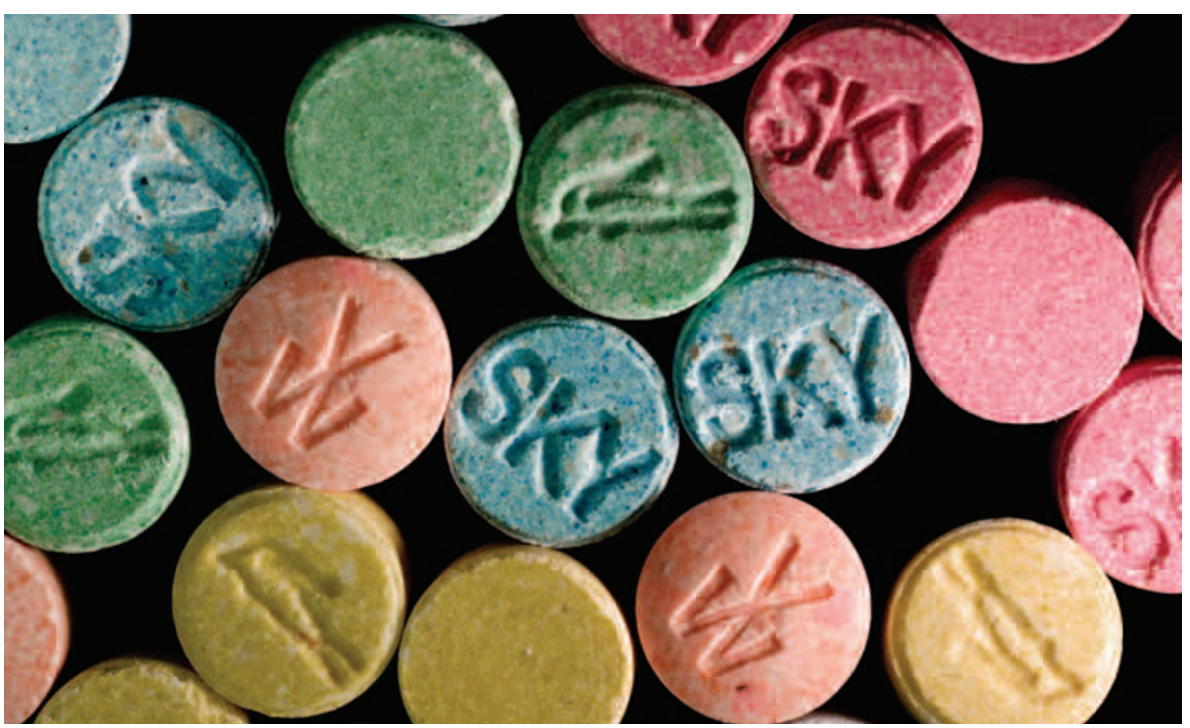

Fig. 2 Ecstasy tablets have different colours, shapes and logos

Although the general impression is that ecstasy is a rather harmless drug, it can have acute toxic effects. From 1996 to 2002, 202 ecstasy-related deaths have been registered in England and Wales, and ecstasy was apparently the sole drug implicated in 17\% of these deaths. ${ }^{15}$ The induced neuromuscular stimulation results in muscle rigidity and breakdown of muscle fibres (rhabdomyolysis). This degradation of muscle tissue may raise the body temperature. In combination with prolonged vigorous dancing in hot and crowded clubs, this could lead to fulminant hyperthermia with body temperatures as high as $44^{\circ} \mathrm{C} .^{4,16}$ Fulminant hyperthermia has a poor prognosis, as it might lead to further rhabdomyolysis, acute renal and liver failure, and disseminated intravascular coagulation., ${ }^{4,5,16-18}$ Therefore, it is important that victims with symptoms of ecstasy intoxication are cooled as soon as possible. ${ }^{19}$

The combination of hyperthermia and the warm environment of dance clubs results in an excessive water intake. However, ecstasy also stimulates the secretion of antidiuretic hormone (ADH). This combination of increased water intake and impaired renal excretion will dilute body fluids, causing hyponatraemia and cerebral oedema with insults and coma. ${ }^{20}$ Therefore, consumption of isotonic fluids (such as sport drinks) instead of water is recommended, as isotonic fluids will help to replace minerals and reduce the risk of developing hyponatraemia. ${ }^{2}$
The addiction risk of ecstasy seems to be limited. Animal studies, however, suggest that long term use of ecstasy is toxic to nerve cells. ${ }^{14}$ Recent evidence suggests that serotonin-neurotoxicity may also occur with repeated MDMA use in humans. ${ }^{21}$ This could explain the progressive memory deficits, observed in a group of 15 volunteers over a 12-month period in which ecstasy was used at a mean frequency of 2.4 times a month. ${ }^{4}$

\section{Oral aspects}

Most oral effects of ecstasy that have been documented are case reports, although the relation with xerostomia and bruxism has been investigated more systematically.

\section{Xerostomia and dental erosion}

In several studies 93-99\% of the users experienced a dry mouth during an ecstasy induced trip. ${ }^{22-24}$ This xerostomia can persist up to 48 hours after consumption of ecstasy, ${ }^{14,24-26}$ especially in females. ${ }^{27}$ Although the incidence of dry mouth did not differ between one to three time users and individuals that used ecstasy multiple times, ${ }^{28}$ the risk of acute xerostomia seems dose-related. A dry mouth or throat was reported by $25 \%$ of healthy volunteers two hours after administration of $0.5 \mathrm{mg}$ MDMA/ $\mathrm{kg}$, and by $88 \%$ after a dose of $1.5 \mathrm{mg} /$ $\mathrm{kg}$. The xerostomia also persisted longer after the higher dose. ${ }^{29}$

To relieve the xerostomia, hyperthermia and dehydration from vigorous dancing, ecstasy use is associated 


Table 1 Mental and systemic
effects associated with use of $\mathbf{3 , 4}$
methylenedioxymethamphetamine
MDMA) ${ }^{5,32}$

with an excessive consumption of soft drinks. These sugar-containing acidic drinks could increase caries rates and are potentially erosive to the teeth. ${ }^{24,30-32}$ The risk of enamel erosion is enhanced by the reduced saliva secretion and buffering capacity. ${ }^{24}$ Furthermore, 16\% of Australian ecstasy users reported nausea and vomiting as a side effect, which could also enhance the enamel erosion. $^{24,28}$ To reduce the risk of dental erosion fluoride mouthwash and sugarfree chewing gum can be used. ${ }^{30}$

\section{Bruxism}

Administration of a single or repeated dose of MDMA in rats induced a partial inhibition of the jaw opening reflex. ${ }^{33}$ Although these results cannot directly be extrapolated to man, they are in line with the frequently reported jaw clenching and grinding of teeth during ecstasy use (50-89\%). . $2,22-24,26,27,29$ Similar percentages of ecstasy users claimed

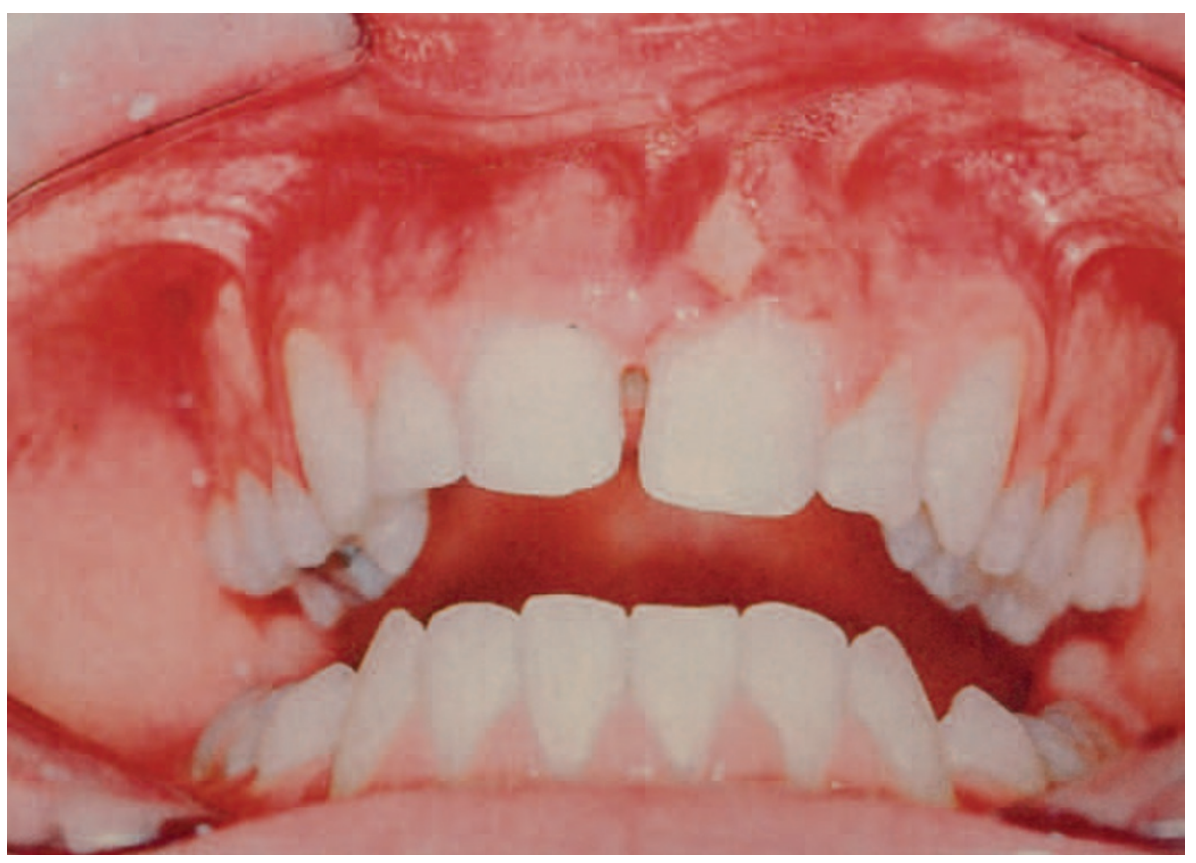

Fig. 3 Mucosal fenestration of the attached gingiva of the 21 after local application of ecstasy (courtesy of W. J. Brazier)

they felt pain or tenderness in their jaw muscles. ${ }^{23}$

The clenching and grinding persisted for many hours after the 'trip'. Jaw clenching was still present after 24 hours in 19 to $40 \% .^{14,23,26,27}$ In one study, $29 \%$ reported jaw clenching even after 48 hours. ${ }^{26}$ Ecstasy had no gender effect on the incidence of jaw clenching. ${ }^{27}$ Two studies suggest that larger doses of ecstasy are related to more severe jaw clenching. ${ }^{2,28}$ Chewing gum, lollies or even (baby) soothers are frequently used to reduce trismus and bruxism. ${ }^{34}$ Surprisingly, one individual reported that he experienced chronic trismus prior to taking MDMA. While taking MDMA, the trismus stopped but returned once the ecstasy effect wore off. ${ }^{35}$

Tooth wear through the enamel into the underlying bone occurred in 60\% of ecstasy users, but in only $11 \%$ of nonusers. $^{24}$ This tooth wear was observed predominantly in the premolar and molar region. Incisal wear was not different from control subjects. ${ }^{22,24,25}$ The severity of tooth wear in ecstasy users was especially increased for the lower first molars. ${ }^{25}$ This distribution of tooth wear suggests that ecstasy caused clenching rather than grinding. ${ }^{35}$ The combination the ecstasy induced -clenching, excessive consumption of acidic soft drinks and decreased lubrication of saliva - will result in more tooth wear than in control groups. ${ }^{35}$

\section{Oral mucosa}

In an interview with 466 regular ecstasy users, 2.3\% reported that they got mouth ulcers 24 hours later and 8.2\% 24-48 hours later. ${ }^{26}$ The mucosal involvement is also illustrated by several case reports.

Brazier and co-workers ${ }^{32}$ described a case report of a 15-year-old boy with a painful swelling of the maxillary labial vestibule (Fig. 3). Both maxillary central incisors exhibited Grade II mobility and were tender to percussion. In the presence of his parents, he denied topical application of any agent. Incision and drainage of the presumed acute dentoalveolar abscess was performed. Two days later, the swelling had reduced in size and the symptoms subsided. Mucosal fenestration of the attached gingiva was visible with exposure of alveolar bone and roots of the 21 and 22. All maxillary incisors still exhibited Grade II mobility. Radiographic examination showed no loss of bone support. Subsequently, the boy was referred to a dental hygienist for oral hygiene instruction, scaling, and polishing. During this visit he acknowledged that he had stored an ecstasy tablet in the upper anterior vestibule adjacent to the site of periodontal destruction, one day prior to the onset of the symptoms. This enabled the diagnosis of 'necrotising gingivitis related to use of ecstasy'. 
After an intensive oral hygiene treatment, fluoride varnish application and fixation of the mobile incisors, the mucosal ulceration had healed after one week and four months later the teeth were immobile again. At that time, the patient no longer had complaints but a localised 2-3 $\mathrm{mm}$ defect of the alveolar gingivae remained. This defect could be due to local ischaemic vasoconstrictive activity of ecstasy. The site of application may also have played a role: the labial vestibule is not keratinised and is poorly exposed to (diluting) saliva.

Another case report concerns a 14year-old boy with a two year history of use of cocaine, ecstasy, speed, heroin, alcohol and tobacco. ${ }^{37}$ He rubbed these drugs on his gingiva frequently and - as a result - gingival and mucosal ulcerations and necrosis developed. The authors blame this to the use cocaine, but of course the oral health problems could also be the result of ecstasy use.

A third patient rapidly developed widespread perioral and intraoral swelling within two hours after swallowing one ecstasy tablet. ${ }^{38}$ The extensive oedema involved the upper and lower labial mucosa, bilateral buccal mucosa, dorsum of the tongue and the bilateral tonsillar regions. The appearance was greyishwhite without evidence of ulceration or exudation. He was treated with corticosteroids, antibiotics and chlorhexidine mouthwash. After ten days, the mucosal reaction had completely disappeared.

\section{Other orofacial aspects}

Ecstasy users report more frequently TMJ tenderness compared to individuals who use other illicit drugs. ${ }^{23}$ In the same study, a non-significant increase was observed for sensitive teeth and for cheeks, tongue or lip biting. ${ }^{23}$ The increased consumption of chewing gum and carbonated drinks containing sugar ${ }^{22,25}$ may lead to extensive cervical caries. ${ }^{32}$

Forty-five percent of ecstasy users report speech changes, ${ }^{35}$ and one third palpitations. ${ }^{4}$ Nystagmus and motor tics, presenting as trembling of the face, occur less frequently $(10 \%$ and 5\%, respectively)..$^{35}$

The incidence of paresthesias, which may manifest around the lips, seems to be related to the dose of ecstasy. Two hours after $1.5 \mathrm{mg} / \mathrm{kg}, 75 \%$ of the individuals reported paresthesias, twice the frequency observed after ingestion of $0.5 \mathrm{mg} / \mathrm{kg} .{ }^{29}$ A dose-related effect is also suggested by a study comparing one to three times users and multiple users. The severity of oral side effects was positively correlated with both the total number of doses consumed and the frequency of use. $^{28}$ In addition, individuals that use ecstasy regularly in combination with other drugs reported more dental problems than those that combine ecstasy only with alcohol or cannabis. ${ }^{39}$

\section{Saliva}

In general, blood and urine sampling are used for monitoring ecstasy consumption. Saliva, however, has several advantages over these fluids: it can be collected easily, in a painless non-invasive and observable way without risk of infection. ${ }^{40}$ Two to four hours after use, the concentration of ecstasy in saliva is maximal. ${ }^{41}$

For the detection of ecstasy in saliva, an immunochemical test strip is available ('Drugwipe ${ }^{\circledR}$ '). The strip can be wiped directly on the tongue. It is also possible to collect saliva in a plastic tube and subsequently immerse the strip in the collected saliva. Direct application of the Drugwipe ${ }^{\circledR}$ on the tongue could detect use of MDMA by healthy volunteers for up to ten hours. ${ }^{42}$ Chances of a positive test decreased rapidly when the test was performed more than 1.5 hours after use of MDMA. However, if the Drugwipe ${ }^{\circledR}$ was immersed in a tube with collected saliva, ecstasy use could still be demonstrated in five of eight volunteers. Determining ecstasy in saliva with the Drugwipe ${ }^{\circledR}$ agrees well with the determination of ecstasy with gas chromatography - mass spectrometry, the most widely used method to confirm positive results. ${ }^{43}$ Liquid chromatography - mass spectrometry is rarely applied for the detection of ecstasy in saliva. ${ }^{44}$

Unfortunately, the use of saliva for determination of ecstasy also has disadvantages. Since ecstasy is usually ingested as a tablet, this can lead to (extremely) high salivary concentrations, not related to the state of intoxication. ${ }^{44}$ In addition, the ecstasy concentration is also affected by the secretion rate and $\mathrm{pH}$ of saliva. ${ }^{13}$ The salivary flow rate and $\mathrm{pH}$ both depend on the collection method of the saliva specimen. Ecstasy users suffer from xerostomia and may find it difficult to provide an adequate unstimulated saliva specimen for an effective test. ${ }^{41}$ When saliva sampling occurs under stimulating conditions, both volume and $\mathrm{pH}$ will increase resulting in a lower salivary ecstasy concentration. ${ }^{44}$ Therefore, if quantitative results are required, standardised sampling of saliva is a prerequisite. Nevertheless, detection of ecstasy in saliva seems a good alternative to the use of urine or blood for this purpose.

\section{Dental treatment}

Dental treatment of ecstasy induced tooth wear is not only time consuming and potentially expensive, ${ }^{22}$ but ecstasy use may also interfere with the dental treatment. For example, MDMA has slight interactions with monoamineoxidase inhibitors and tricyclic antidepressants, which may be prescribed in the management of temporomandibular joint pain. ${ }^{30,32}$ If dental treatment must be provided to a patient who has recently used ecstasy, the dentist must be cautious in administering a local anaesthetic containing epinephrine. Ecstasy induces a systemic increase in blood pressure, which may be potentiated by this vasoconstrictor and/or anticipated stress of dental treatment. ${ }^{45}$

Therefore, dentists should try to identify patients that use ecstasy. However, a problem is that patients may not report use of ecstasy. A nonconfrontional medical history taking with 'judgement-free' questioning of possible use is essential. ${ }^{46}$

Once ecstasy use has been determined, the (oral) side effects and discontinuation of ecstasy use can be discussed. ${ }^{30}$ Dental side effects can be counteracted by preventive measures as a fluoride mouthwash, use of sugar-free chewing gum and provision of a soft splint. ${ }^{30}$

1. Cohen R S. Subjective reports on the effects of the MDMA ('ecstasy') experience in humans. Prog Neuropsychopharmacol Biol Psychiatry 1995; 19: 1137-1145.

2. Zervogiannis $F \mathrm{H}$, Wiechers $\mathrm{E}$, Bester $\mathrm{G}$. The ' $\mathrm{E}$ ' in rave: a profile of young ecstasy (MDMA) users. $S$ Afr J Psychol 2003; 33: 162-169.

3. McDowell D M, Kleber H B. MDMA: its history and pharmacology. Psychiatr Ann 1994; 24: 127-130.

4. Cole J C, Sumnall H R. Altered states: the clinical effects of ecstasy. Pharmacol Ther 2003; 98: 35-38. 
5. Hall A P, Henry J A. Acute toxic effects of 'ecstasy' (MDMA) and related compounds; overview of pathophysiology and clinical management. BrJ Anaesth 2006; 96: 678-685.

6. Baggott $M$, Heifets $B$, Jones R T et al. Chemical analysis of ecstasy. J Am Med Assoc 2000; 284: 2190.

7. Tossmann $\mathrm{P}$, Boldt $\mathrm{S}$, Tensil M D. The use of drugs within the techno party scene in European metropolitan cities. Eur Addict Res 2001; 7: 2-23.

8. United Nations Office on Drugs and Crime. World drug report 2007. pp 161-165.

9. Newbury-Birch D, Lowry R J, Kamali F. The changing patterns of drinking, illicit drug use, stress, anxiety and depression in dental students in a UK dental school: a longitudinal study. Br Dent J 2002; 192: 646-649.

10. Underwood B. Fox K. A survey of alcohol and drug use among UK based dental undergraduates. Br Dent J 2000; 189: 314-317.

11. Underwood B, Fox K, Nixon PJ. Alcohol and drug use among vocational dental practitioners. Br Dent J 2003; 195: 265-268.

12. Torre R de la, Farré M, Navarro M et al. Clinical pharmacokinetics of amfetamine and related substances, monitoring in conventional and nonconventional matrices. Clin Pharmacokinet 2004; 43: 157-185.

13. Navarro M, Pichini S, Farré M et al. Usefulness of saliva for measurement of 3,4-methylenedioxymethamphetamine and its metabolites: correlation with plasma drug concentrations and effect of salivary pH. Clin Chem 2001; 47: 1788-1795.

14. Vollenweider FX, Gamma A, Liechti M, Huber T. Psychological and cardiovascular effects and short-term sequelae of MDMA ('ecstasy') in MDMA-naive healthy volunteers. Neuropsychopharmacology 1998; 19: 241-250.

15. Schifano F, Oyefeso A, Carkery J et al. Death rates from ecstasy (MDMA, MDA) and polydrug use in England and Wales. Hum Psychopharmacol 2003; 18: $519-524$

16. Colado M I, Williams J L, Green A R. The hyperthermic and neurotoxic effect of 'Ecstasy' (MDMA) and 3,4 methylenedioxyamphetamine (MDA) in the dark agouti (DA) rat, a model of the CYP2D6 poor metabolizer phenotype. Br J Pharmacol 1995; 115: 1281-1289.

17. Screaton G R, Cairns H S, Sarner M et al. Hyperpyrexia and rabdomyolysis after MDMA ('ecstasy') abuse. Lancet 1992; 339: 677-678.

18. Kalant $H$. The pharmacology and toxicology of 'ecstasy'(MDMA) and related drugs. Can Med Assoc J 2001; 165: 917-928.
19. Gaffin S L, Gardner J W, Flinn S D. Cooling methods for heatstroke victims. Ann Intern Med 2000; 132: 678.

20. Halperin M L, Goldstein M B. Sodium and water. In Halperin M L, Goldstein M B (eds). Fluid, electrolyte, and acid-base physiology. pp 227-329. Philadelphia: WB Saunders Company, 1999.

21. McCann U D, Szabo Z, Scheffel U, Dannals R F, Ricaurte G A. Positron emission tomographic evidence of toxic effect of MDMA (ecstasy) on brain serotonin neurons in human beings. Lancet 1998; 352: 1433-1437.

22. Redfearn P J, Agrawal N, Mair L H. An association between the regular use of 3,4 methylenedioxymethamphetamine (ecstasy) and excessive wear of the teeth. Addiction 1998; 93: 745-748.

23. McGrath C. Chan B. Oral health sensations associated with illicit drug abuse. Br Dent J 2005; 198: 159-162.

24. Milosevic A, Agrawal N, Redfearn P J, Mair L H. The occurrence of toothwear in users of ecstasy $(3,4$ MethyleneDioxyMethAmphetamine). Community Dent Oral Epidemiol 1999; 27: 283-287.

25. Nixon P J, Youngson C C, Beese A. Tooth surface loss: does recreational drug use contribute? Clin Oral Investig 2002; 6: 128-130.

26. Verheijden S L, Henry J A, Curran H V. Acute, sub-acute and long-term subjective consequences of 'ecstasy' (MDMA) consumption in 430 regular users. Hum Psychopharmacol 2003; 18: 507-517.

27. Liechti M E, Gamma A, Vollenweider F X Gender differences in the subjective effects of MDMA. Psychopharmacology 2001; 154: 161-168.

28. Solowij N, Hall W, Lee N. Recreational MDMA use in Sydney; a profile of 'ecstasy' users and their experiences with the drug. Br J Addict 1992; 87: 1161-1172.

29. Harris D S, Baggott M, Mendelson J H, Mendelson $J E_{\text {, Jones } R} \mathrm{~T}$. Subjective and hormonal effects of 3,4-methylenedioxymethamphetamine (MDMA) in humans. Psychopharmacology 2002; 162: 396-405.

30. Duxbury A J. Ecstasy - dental implications. Br Dent J 1993; 175: 38

31. Murray M C, Wilson N H F. Ecstasy related tooth wear. Br Dent J 1998; 185: 264.

32. Brazier W J, Dhariwal D K, Patton D W, Bishop K. Ecstasy related periodontitis and mucosal ulceration - a case report. Br Dent J 2003; 194: 197-199.

33. Arrue A, Gómez F M, Giralt M T. Effects of 3,4 methylenedioxymethamphetamine (ecstasy) on the jaw-opening reflex and on the $\alpha 2$-adrenoceptors which regulate this reflex in the anesthetized rat. Eur J Oral Sci 2004; 112: 127-133.
34. Doyon S. The many faces of ecstasy. Curr Opin Pediatr 2001; 13: 170-176.

35. Liester M B, Grob C S, Bravo G L, Walsh R N Phenomenology and sequelae of 3,4-methylenedioxymethamphetamine use. J Nerv Ment Dis 1992; 180: 345-352.

36. Greer G, Tolbert R. Subjective reports of the effects of 3,4-methylenedioxymethamphetamine in a clinical setting. J Psychoactive Drugs 1986; 18: 319-327.

37. Parry J, Porter S, Scully C, Flint S. Mucosal lesions due to oral cocaine use. Br Dent J 1996; 180: 462-464.

38. Ahmed M, Islam S, Hoffmann G R. Widespread oral and oropharyngeal mucosal oedema induced by ecstasy (MDM): a case for concern. Br J Oral Maxillofac Surg 2005; 45: 496-498.

39. Chinet L, Stephan P, Zobel F, Halfon O. Party drug use in techno nights: a field survey among Frenchspeaking Swiss attendees. Pharmacol Biochem Behav 2007; 86: 284-289.

40. Veerman E C I, van den Keijbus PA M, Vissink $A$, Nieuw Amerongen A V. Human glandular salivas: their separate collection and analysis. Eur J Oral Sci 1996; 104: 346-352.

41. Samyn N, Boeck G de, Wood M et al. Plasma, oral fluid and sweat wipe ecstasy concentrations in controlled and real life conditions. Forensic Sci Int 2002; 128: 90-97.

42. Pichini S, Navarro M, Farré M et al. On-site testing of 3,4-methylenedioxymethamphetamine (ecstasy) in saliva with drugwipe and drugread: a controlled study in recreational users. Clin Chem 2002; 48: 174-176.

43. Mancinelli R, Gentili S, Guiducci M S, Macchia T. Simple and reliable high-performance liquid chromatography fluorimetric procedure for the determination of amphetamine-derived designer drugs. J Chromatogr B Biomed Sci App/ 1999; 735: 243-253.

44. Mortier K A, Maudens K E, Lambert W E et al. Simultaneous, quantitative determination of opiates, amphetamines, cocaine and benzoylecgonine in oral fluid by liquid chromatography quadrupole-time-of-flight mass spectrometry. J Chromatogr B Biomed Sci App/ 2002; 779: 321-330.

45. Goodchild J H. Methamphetamine abuse and the impact on dental health. Dent Today 2007: 26: 124-131.

46. Birnbach D J. Anesthetic management of the drugabusing parturient: are you ready? J Clin Anesth 2003; 15: 325-327. 